\title{
Proteção ao Meio Ambiente. Uma Prioridade Alemã
}

\section{Renata Lucas de Camvalho}

Advogada, Faculdade de Direito Candido Mendes-Centro (1993 - Rio de Janeiro), Pós-graduação em Direito Empresarial pela Faculdade de Direito Candido Mendes-Ipanema (1995, Rio de Janeiro), aluna da Faculdade de Direito em Hannover, Alemanha (Universität Hannover

Rechtswissenschaft) desde agosto de 1997.

\section{Introdução}

1.

o momento em que vivemos as pre ocupações com a proteção ao meio ambiente atingiram níveis bastante elevados. Governantes do mundo inteiro voltam-se para este problema com grande afinco, na tentativa de reverter o processo de degradação ambiental. A grave situação atual faz com que se torne indispensável que os danos ambientais sejam reparados com rapidez e de modo adequado. Deste modo que o quadro geral de degradação das já pre cárias condições em que a vida é sustenta$\mathrm{da}$ nã̉o seja ainda mais comprometido, sob pena de se configurar um cenário de irreversibilidade.

$\mathrm{Na}$ Alemanha, enfoque do nosso estudo, o pensamento de proteção ao meio ambiente e o desdobramento de uma lei particularmente ligada a este assunto teve início em 1971 com o Programa do Meio

Ambiente do Governo Alemão (Das Umweltprogramm der Bundesregierung). $\mathrm{O}$ Programa definia a proteção ao meio ambiente como o conjunto de medidas, que são necessárias para assegurar ao homem um meio ambiente, que o possibilita de levar uma vida saudável; para o solo, o ar e as águas, as plantas e os animais serem protegidos dos efeitos prejudiciais da usurpação do homem; e para os danos ou prejuízos da usurpação do homem serem abolidos ou evitados.

Estes princípios básicos foram adotados no Relatório do Meio Ambiente do Governo Alemão (Umweltbericht der Bundesregierung), escrito em 1976 e serviram como base para as leis hoje existentes sobre meio ambiente.

Os cuidados ambientais na Constituição Alemã (Grundgesetz für die Bundesrepublik Deutschland - GG) estão no art. 20a que regula a proteção ao meio ambiente e se responsabilisa pela geração futura.

\section{Princípios do Direito de Proteção ao Meio Ambiente}

Derivados do Programa e do Relatório do Meio Ambiente do Governo Alemão surgiram os seguintes princípios: 


\section{Princípio da Precaução \\ II. Princípio da Causalidade \\ III. Princípio da Cooperação}

\section{Princípio da precaução}

O Princípio da Precaução pode ser visto como um modelo moderno de política do meio ambiente. Tem como objetivo evitar resultados possíveis do desgaste ambiental, através de prospectivos ajustes e com os recursos naturais disponíveis as segurar uma base ecológica a longo prazo. O Princípio da Precaução estabelece uma zona de segurança em relação aos perigos limiares ao meio ambiente.

\section{Princípio da causalidade}

O Princípio da Causalidade significa que um prejuízo efetivado ao meio ambiente produz uma responsabilidade financeira para quem o causou. Gerando não só uma responsabilidade financeira como consequências legais no âmbito civil.

\section{Princípio da cooperação}

O Princípio da Cooperação basea-se no pensamento que a proteção ambiental não é somente um dever do Estado, mas sim o esforço de um trabalho em conjunto entre a sociedade e o Estado. Para tal é preciso que a execução das normas legais sejam facilitadas e a perícia no âmbito social seja feita de uma maneira proveitosa. Um exemplo foi a espontânea participação de indústriais no acordo para a limitação na produção de um tipo de cloro na fabricação de produtos de limpeza, por este ser prejudicial ao meio ambiente.

\section{Principais Instrumentos do Direito de Proteção Ambiental}

Os principais instrumentos do direito de proteção ambiental são: o Planejamen to, o Procedimento Governamental Direto e o Indireto.

\section{Planejamento}

O planejamento do meio ambiente, como ponto principal de precaução para a política ambiental, facilita a coordenação entre as causas ambientais complexas com os diversos objetivos e interesses do homem (\$29 Kreislaufwirtschafts-und Abfallgesetz - KrW AbfG). Serve também como instrumento de controle na execução e construção de rodovias, estradas de ferro e aeroportos, por exemplo, analisando a interação e consequências com o meio ambiente (\$31 II Kreislaufwirtschafts-und Abfallgesetz - KrW AbfG). Para que um planejamento seja aceito é preciso que passe pelo Processo de Licenciamento do $\mathrm{Pla}$ no, que tem como objetivo a apreciação $e$ legalização de um projeto.

\section{Procedimento governamental direto}

Podem ser qualificados de Procedimentos Governamentais Diretos os Instrumentos de Controle Administrativos, as Proibições e Ordens legais, como também as Obrigações Ambientais. Impõem para os seus destinatários um certo tipo de comportamento, que somente possibilita aceitar a exigência ditada pelo Estado, ou desistir da atividade.

\section{IIa. Instrumentos de controle administrativos}

Os instrumentos de controle administrativos são baseados na notificação obrigatória, nas licenças, no mandado de revogação e na competência de fiscalização (por meio do Poder Executivo). Através da notificação obrigatória, a Administração recebe informações, que servem como contínua fiscalização das atividades possivelmente nocivas ao meio ambiente (Umweltstatistikgesetz - UStatG).

As licenças são dadas para a execução de um projeto após o cumprimento de normas já pré-estabelecidas pelo governo que proíbem atividades sabidamente deletérias ao meio ambiente. De modo que possíveis danos ao meio ambiente por meio da instalação de uma indústria, por exemplo, sejam minimizados através da execução de normas técnicas ( $\$ 7$ Wasserhaushaltsgesetz - WHG; §4 Bundes-Immissionsschutzgesetz - BImSchG; §7 Atomgesetz AtomG).

Podemos destacar duas importantes licenças que são concedidas após as seguintes restrições: 1 . da proibição preventiva e 2. da proibição repressiva. A proibição preventiva existe para proteger os recursos naturais. Entretanto o Estado concede algumas licença para certas atividades que embora prejudiquem o meio ambiente, favorecem outras atividades sócio-econômicas. ( $\$ 6$ Bundes-Immissionsschutzgesetz BImSchG). A proibição repressiva existe para bloquear uma atividade que está sendo prejudicial ao meio ambiente. Uma vez que o nível de poluição da atividade for controlada, a proibição é revogada (\$7 II Atomgesetz - AtomG).
A licença é concedida através dos processos de admissão de um projeto. $O$ processo simples de autorização caracteriza-se por ser flexível na sua execução uma vez que avalia projetos normalmente não prejudiciais ao meio ambiente. Logo, este pode ser conduzido de maneira conveniente para os interessados e com maior rapidez ( $\$ 10$ e seg. Verwaltungsverfahrensgesetz $\mathrm{VwVfG})$.

O processo formal de autorização dis. põe de normas legais detalhadas do proces so administrativo. O primeiro passo é entrar com o pedido escrito de autorização junto com os documentos necessários e requerer uma publicação, tornando público o projeto para todos. Durante o decorrer da publicação pode ser apresentada uma réplica por um terceiro interessado, que será discutida e decidida em uma Audiência Pública. O direito de participação no processo por um terceiro, pode ser tanto em favor de um in teresse individual, quanto de um interesse coletivo, em que ele atua como representante. O processo termina com a conces são, completa ou em parte, ou a negação da autorização, cabendo rẹcurso da decisão ( $\$ 63$ e seg. Verwaltungsverfahrensgesetz . $\mathrm{VwVfG})$.

O processo de licenciamento do plano é um processo de autorização especial para projetos que reivindicam e influenciam um espaço, como por exemplo, a cons. trução de uma auto estrada.

O seu andamento basea-se no processo formal de autorização com a apresentação do plano junto com os devidos documentos, o pedido de publicação oficial, a oportunidade de imposição de réplica 
seguida da Audiência Pública e sentença final ( $\$ 72$ e seg. Verwaltungsverfahrensgesetz - VwVfG).

Os processos no direito ambiental alemão não possuem uma regra fixa, pois não são baseados em somente um código de leis. Para cada caso, existe uma lei e uma instituição responsável diferente. Entretanto todo projeto tem que passar pela Avaliação do Impacto Ambiental, que identifica descreve e avalia os efeitos, diretos e indi retos, de um projeto no meio ambiente (Umweltverträglichkeitsprüfungsgesetz UVPG).

O mandado de revogação serve para cessar atividades que estão prejudicando o meio ambiente, mesmo que estas já este jam em andamento. É exercido quando, apesar das inúmeras medidas preventivas ao meio ambiente, uma certa atividade atin ge um ponto crítico com relação ao dano ambiental, necessitando de um ato repres sivo radical e imediato.

A competência de fiscalização do Estado na proteção ao meio ambiente tem dois deveres fundamentais. $O$ primeiro, serve como controle único com relação ao cumprimento das exigências de comportamento no direito ambiental pelas pessoas civis e jurídicas, através das afirmações oficiais e dos decretos proibindo a execução de ações nocivas ao meio ambiente. Além disso, tem a função de observar o meio ambiente, ou seja, registrar continuamente o desenvolvimento da situação ambiental.

IIb. Proibições, ordens legais e obrigações

A Proibição Legal é declarada, quando o legislador quer impedir um prejuízo ao meio ambiente. A Ordem Legal tem apenas um caráter de apelo, como por exemplo, sugerir o uso de produtos compatíveis com o meio ambiente. Tanto a proibição quanto a ordem legal são geridos através do Poder Legislativo.

As obrigações no direito ambiental alemão são divididas em materiais e formais, que se distinguem por serem originárias ou derivadas e fazem parte do Poder Executivo

As obrigações materiais impõem aos cidadãos uma atitude de proteção e conservação do meio ambiente. São formadas pelas obrigações de realização (fazer) e de omissão (não fazer). Um exemplo de obrigação de fazer é o lixo jogado fora. $O$ cidadão tem a obrigação de separar o lixo (vidro, papel, plástico, resto de comida) e o Estado de tratá-lo adequadamente.

As obrigações formais, por outro lado, estão relacionadas com a fiscalização do Estado nas suas obrigações para com a pessoa física e jurídica com o objetivo de evitar o dano ambiental. Logo, existe por parte do cidadão uma responsabilidade civil com relação ao controle e preservação do meio ambiente.

\section{Procedimento \\ governamental indireto}

Os instrumentos do Procedimento Governamental Indireto são: a Informação, - Apelo e a Advertência; as Subvenções Diretas e Indiretas; os Tributos; os Acordos e as normas de Responsabilidade. Este procedimento serve para mobilizar um interesse comum na proteção ao meio ambiente e é uma forma de conduta legal.

\section{IIIa. Informação, apelo e advertência}

É dever do Estado fornecer e dar acesso as informações públicas sobre questões ambientais (Umweltinformationsgesetz - UIG). Não somente através de relatórios sobre a política do meio ambiente, como também aconselhando o cidadão, por exemplo, a poupar energia, usar produtos menos nocivos ao meio ambiente, ou utilizar meios de transportes públicos. A informação pública pode ser efetuada por meio de propagandas que apontam os prejuízos realizados ao meio ambiente e soluções para diminuí-los ou evitá-los

Através deste programa educativo o Estado faz o Apelo para uma conduta e uma consciência ambiental. Além disso, o Estado exige que haja uma Advertência para a população com relação aos produtos que possam ser maléficos ao meio ambiente. Como por exemplo a advertência escrita nos produtos de limpeza e outros similares para que o consumidor, através da sua "consciência ambiental", tenha a informação necessária para que possa escolher outro produto menos prejudicial a natureza.

\section{IIIb. Subvenções diretas e \\ indiretas}

As subvenções são auxílios pecuniários concedidos pelo Governo. As subvenções diretas são financiadas através dos subsídios, doações ou empréstimos reembolsáveis. As subvenções indiretas tem como objetivo a redução de impostos de firmas ou empresas.

Com a ajuda financeira e o pagamento deduzido dos impostos, os favorecidos podem investir em produtos e empreendimentos mais benéficos ao meio ambiente.

\section{IIIc. Tributos}

Entende-se por tributo ambiental um rendimento em dinheiro arrecadado pelo direito público através de imposto, taxa e contribuição. Podem ser arrecadados para o financiamento de projetos de proteção ao meio ambiente ou como recursos para o incentivo da política ambiental.

A política ambiental tem interesse de lançar os impostos sobre: os detritos, a poluição sonora e as radiações que causam influências sobre pessoas, animais, plantas, construções e semelhantes; e a poluição gasosa que se alastram no ar atmosférico (Bundes-Immissionsschutzgesetz BImSchG).

Os impostos têm como finalidade estimular evitáveis danos ambientais através de invenções e modificações nos produtos já existentes no mercado. Exemplo é o imposto sobre veículos motorizados que proporcionou a criação do catalisador diminuindo consequentemente o grau de poluição na combustão do combustível dos veículos motores (imposto de condução). Além disso, os impostos podem ser utilizados na recuperação de fontes naturais já lesadas (imposto de compensação).

\section{IIId. Acordos}

Os acordos são contratos celebrados entre o Estado e pessoas civis ou jurídicas, acertando o cumprimento de deveres e obrigações, por ambas as partes (Princípio da Cooperação). Uma das grandes vantagens do acordo é que, sendo uma norma infor- 
mal da Administração, evita as, às vezes, demoradas normas formais legais.

\section{IIIe. Normas de}

\section{responsabilidade}

A norma geral de responsabilidade civil que protege a propriedade e a saúde encontra-se no parágrafo 823 do Código Civil Alemão (Bürgerliches Gesetzbuch $\mathrm{BGB}$ ).

Esta pode ser utilizada como um dos fundamentos para o ressarcimento de $\mathrm{da}$ nos causados contra o meio ambiente. Gera a obrigação de reparação de dano (obrigação de compensação) quando ocorre: lesão à bens da vida e direitos ( $\$ 823 \mathrm{I}, \mathrm{BGB}) \mathrm{e}$ infração de outras leis que visam a proteção do meio ambiente (\$823 II, BGB). Mas é necessário a comprovação de ato ilegal e culposo por parte do agente.

A lei específica de responsabilidade com relação aos danos ao meio ambiente é a Lei de Responsabilidade Ambiental (Umwelthaftungsgesetz - UmweltHG), de 10 de dezembro de 1990. Foi criada com o objetivo de aperfeiçoar os tipos legais de responsabilidade, facilitar a prova da causalidade, obter o ressarcimento do dano mais rapidamente e realizar projetos de proteção ambiental. Os pressupostos para a responsabilidade são que a atividade danosa esteja listada no Anexo 1 da UmweltHG, que a agressão ao meio ambiente descenda destas instalações e que exista uma ligação de causalidade entre o fato danoso e a lesão ambiental.

As hipóteses de exclusão de responsabilidade são: danos causados por força maior; danos não substanciais de acordo com as circunstâncias locais, desde que a instalação esteja desenvolvendo suas atividades adequadamente; danos ocorridos antes da entrada da Lei em vigor, em 1 de janeiro de 1991

Para a garantia da responsabilidade de algumas instalações especificamente perigosas, que estão enumeradas no Anexo 2 da UmweltHG, é obrigatório a tomada de precauções de segurança, como obter um seguro de responsabilidade civil.

\section{Direito europeu ambiental}

Não podemos deixar de citar o direito europeu ambiental. Entre 1972 e 1987 foram utilizadas pela Comunidade Européia as Atas Legais com 200 regras ambientais. Com a celebração da Ata Comum Européia (EEA - Einheitlichen Europäischen Akte) foi admitido em 1987, o título de política ambiental, art. 130r e segs. do Tratado da Comunidade Européia (EGV - Vertrag zur Gründung der Europäischen Gemeinschaft) pelo Tratado da Comunidade Européia de Economia (EWGV - Vertrag zur Gründung der Europäischen Wirtschaftsgemeinschaft).

A política ambiental da Comunidade Européia (art. 130r EGV) contribui para que o meio ambiente seja mantido e prote. gido; que sua qualidade seja melhorada; que a saúde do homem seja protegida; que os recursos naturais sejam empregados de forma cautelosa e razoável, e que medidas sejam promovidas a nível internacional para problemas ambientais, tanto para realizações locais como globais. Apesar de levar em consideração as diferentes realidades das regiões da Comunidade Européia, tende sem dúvida alguma à um alto nível de proteção ambiental (art. 100a III EGV).

Para que uma política ambiental fos se alcançada, a Comunidade Européia aten deu aos dados econômicos e técnicos dos diferentes países, a condição ambiental de cada região da Comunidade, e o desenvol vimento econômico e social da Comunida de no âmbito geral e regional.

\section{Direito ambiental das nações}

Os problemas ambientais assumiram uma dimensão internacional, pois certos episódios tem enorme repercussão fora do território onde se verificam, devido sua amplitude ou gravidade. Como exemplos de acidentes de âmbito internacional podemos citar o de Bhopal, na Índia, em 1984, com 2.000 mortos e mais de 200.000 feridos pelo vazamento de gás tóxico; o de Chernobyl na Ucrânia, em 1986, ocasionando as primeiras mortes por radiação nuclear pela explosão do reator nuclear e cujo material radiotivo cruzou os oceanos e chegou até o Brasil; o derramamento de 30 toneladas de produtos químicos no rio Reno, na Suíca, em 1986, uma das mais graves lesões ambientais já ocorridas na Europa; e o desastre com o petroleiro Norte Americano Exxon Valdez que derramou toneladas de óleo no mar do Alaska.

A Alemanha, devido a sua localidade geográfica com nove países vizinhos, grandes rios internacionais (Reno, Dossau, Mosel, Elbe) e sua localização central que serve de passagem para transportes, tem enorme interesse em efetivar uma política ambiental internacional. Entretanto, vários obstáculos dificultaram um bom anda- mento do direito das nações como a ausência, tanto de uma jurisdição obrigatória como de um orgão executivo central para fiscalização e consolidação de direitos. A reforma deste bom andamento manifestou se na Conferência das Nações Unidas sobre o Meio Ambiente e o Desenvolvimento (United Nations Conference on Environment and Development, UNCED) no Rio de Janeiro, de 3 a 14 de junho de 1992. Teve como participantes 178 países. Um recorde mundial!

A Declaração do Rio foi continuida de da Declaração de Estocolmo. Novo princípios foram criados: a Integração da Proteção Ambiental com o Processo de Desenvolvimento; a Obrigação do Trabalho em Conjunto na Luta contra a Pobreza; a Obrigação de Troca de Informações $\mathrm{Ci}$ entíficas e Promoção de Transferências de Tecnologia; o Princípio da Precaução; o Princípio da Causalidade; a Obrigação do Trabalho em Conjunto com Boa Fé e Espí rito de Parceria. A responsabilidade de cada país foi graduada de acordo com seu poder econômico e financeiro.

O Princípio de Integração da Proteção Ambiental com o Processo de Desenvolvimento tem uma grande importância pois está relacionado com o "desenvolvi mento sustentado", que conforme a definição da Comissão Brutland, da ONU, no relatório "Nosso Futuro Comum", em 1987, é o desenvolvimento social, econômico e cultural que atende as exigências do pre sente sem comprometer as necessidades das futuras gerações.

A Agenda 21 (plano de metas direcionado para o século XXI) concebida 
durante a UNCED tem como objetivo um programa que inclui a criação de mecanismos de financiamento para projetos de preservação ambiental e de transferência de tecnologia da comunidade internacional.

$\mathrm{Na}$ Convenção das Florestas (UNCED, Rio de Janeiro, 1992) ficou decidido que é direito soberano e intransferível do Estado a utilização das florestas, a necessidade de proteger a nação indígena e a necessidade de uma administração para o racionamento da exploração das florestas. E faz parte de alguns programas da Agenda 21. Também criada durante a UNCED a Convenção do Clima, tem como finalidade devido as mudanças climáticas ocorridas no mundo todo, a estabilização das consequências do uso dos gases que causam o efeito estufa e prejudicam a camada de ozônio.

Um fato digno de nota é que, embora a atenção dos ambientalistas tenha subitamente se voltado para o terceiro mundo e para o Brasil, especialmente devido a questão da Floresta Amazônica - os problemas ambientais que são de caráter global - isto é, que afetam toda a comunidade internacional indistintamente - são de responsabilidade quase exclusiva dos Países do primeiro mundo, como a destruição da camada de ozônio, a chuva ácida ou o "efeito estufa". Como bem observado pelo Governo Brasileiro para a Conferência das $\mathrm{Na}$ ções Unidas sobre Meio Ambiente e Desenvolvimento, "além de sofrerem os efeitos negativos desses problemas, sem no entanto usufruir dos benefícios do desenvolvimento, os países do Sul são convocados a compartilhar a responsabilidade e o custo das medidas para atenuar a situação de crise."

\section{Atualidade}

Um dos maiores problemas ambientais que tem ocorrido na Alemanha no últimos anos é o transporte do lixo atômico. A lei atômica (Atomgesetz) declara quais são os elementos radioativos $(\$ 2)$ e como deve ser tratado e eliminado o lixo nuclear (\$9a).

O tratamento do lixo atômico é feito com o objetivo de adequá-lo a uma forma e diminuí-lo até um certo volume para um longo espaço de tempo de armazenagem. Os lixos nucleares de alta radioatividade são envidraçados e soldados em um container de aço e os de média e baixa radioatividade são misturados com betume, cimento ou material plástico e embalados em tonéis. A eliminação do lixo nuclear tem duas etapas: primeiro é remetido para uma armazenagem intermediária até que perca sua meia-vida e depois o Estado estabelece em que instalação será o armazenamento final. A armazenagem é realizada através da colocação do lixo atômico vários metros abaixo do nível da terra entre maciços de sal ou formações de ferro. $\mathrm{Na}$ Alemanha existe duas instalações para armazenagem de material radioativo: em Gorleben, de maciço de sal, e em Konrad, de formação de ferro.

$O$ container que serve para o trans porte e armazenagem intermediária de elementos radioativos de reatores de energia nuclear é chamado de CASTOR (Cask of Storage and Transport of Radioactive Material). Foi desenvolvido na Alemanha e consiste em um corpo de aço fundido com paredes grossas e tampa dupla que deve reter os raios de alta radioatividade. Custa 2,3 milhões de marcos, mede 6,1 metros de altura e 2,5 metros de comprimento, e pesa 112 toneladas. Passou por vários testes de segurança: tiros de arma de fogo, colisão com uma locomotiva a $160 \mathrm{~km} / \mathrm{h}$, temperatura de 800 graus durante 30 minutos e queda de 9 metros de altura. $O$ carregamento do CASTOR é feito com elementos radioativos, já consumidos, dentro do recipiente de extinção de energia nuclear e é fechado debaixo d'água. Depois passa por um processo de limpeza para a descontaminação de resíduos. Em seguida é feita uma verificação se possui raios radioativos e então é transportado para a instalação de armazenagem. Apesar dos inúmeros testes para evitar riscos que possam originar perigos para a população ainda há problemas de segurança com o CASTOR.

No ano passado saíram vários containers para uma instalação de armazenagem, e quando chegaram ao destino, entre cada cinco um estava externamente com um nível de contaminação acima das normas estabelecidas.

A causa da contaminação ainda não foi esclarecida, mas há a suspeita de que quando foi feito o transporte, através da movimentação e diferentes temperaturas podem ter sido liberados resíduos de água radioativa, que apesar da alta precisão de limpeza e a milimétrica junta de calafetagem, podem ter ficado presos na parte externa do container. Assim, os resíduos de água radioativa chegam como aerosol no ar e podem ser inspirados pelas pessoas que estão nas proximidades. Policiais, que protegiam o CASTOR, demonstrantes, que protestavam contra $O$ transporte, o condutor da locomotiva e moradores que estavam ao longo da estrada de ferro, foram expostas a uma fonte de radiação nuclear que futuramente podem causar graves danos a saúde.

$\mathrm{Na}$ tentativa de solucionar o problema, a Sociedade de Segurança dos Reatores Nucleares está estudando um invólucro de plástico para proteger a parte de fora do CASTOR da água radioativa. Por enquanto o transporte de CASTOR está parado mas, com certeza, voltará depois da Eleições para Chanceler na Alemanha, em 27 de setembro deste ano.

\section{Bibliografia}

Barroso, Luis Roberto. "A proteção do meio ambiente na Constituição brasileira." In: Revista Forense. V.317. - Rio de Janeiro: Forense, 1992.

Baum, Fritz. Umweltschutz in der Praxis. 3 a ed. - Munique: R.Oldenbourg Verlag, 1998.

Der Spiegel. Atommüll - Der strahlende Castor. V.22. - Alemanha, 1998.

Der Spiegel. Atomtransporte - Sicher im Plastikhemd. V.36. - Alemanha, 1998.

Internet - http: www.polizei-lg.de allg.htm

Kloepfer, Michael. Umweltrecht. $3^{\mathbf{a}}$ ed. - Alemanha: C. H. Beck, 1989.

KPMG, Deutsche Treuhand Gruppe (HrSG) Umweltrecht in Deutschland. Düsseldorf: IDW - Verlag GmbH, 1995. 
Rebello Filho, Wanderley e Bernardo, Christianne. Guia Prático de Direito Ambiental. - Rio de Janeiro: Editora Lumen Juris, 1998.

Sampaio, Francisco José Marques. "O dano ambiental e a responsabilidade". In: Revista Forense. V.317. - Rio de Janeiro: Forense, 1992.
Sampaio, Francisco José Marques. Responsabilidade Civil e Reparação de Danos ao Meio Ambiente. 2ª ed. - Rio de Ja neiro: Editora Lumen Juris, 1998.

Schmidt, Reiner. Einführung in das Umweltrecht. $4^{\mathrm{a}}$ ed. - Munique: C. $\mathrm{H}$. Beck, 1995.

\section{Direitos Fundamentais de Terceira Geração}

Teoxi OAlbino Lavascki

Professor na Faculdade de Direito da UFRGS

\begin{tabular}{|} 
SUMÁRIO \\
I - Introdução. \\
II - Os direitos fundamentais e sua evo- \\
lução. \\
III - Direitos de primeira geração: a li- \\
berdade. \\
IV - Direitos de segunda geração: a \\
igualdade. \\
V - Direitos de terceira geração: a \\
fraternidade. \\
VI - Os juristas do novo tempo. \\
VII - Conclusão: a valorização das qua- \\
lidades humanas do jurista.
\end{tabular}

idades humanas do jurista.

\section{Introdução}

¿lenidades como esta, de colação de grau, constituem uma espécie de cerimônia no convés de um navio que atraca no porto, chegado de uma longa viagem. Presentes, alguns dos marinheiros responsáveis pela navegada, nosso diretor, os professores e funcionários homenageados. Perfilados, os formandos, viajantes sorridentes, semblantes iluminados, olhar feliz, prontos para o desembarque, a jornada chegou ao seu final; no peito, quiçá um aperto estranho, já uma ponta de nostalgia, porque se aqui é um porto de chegada, é igualmente um lugar de despedidas. Ali, no cais, familiares e amigos, ansiosos para o abraço e o aconchego. Mais adiante, a cidade e as suas ruas, e depois as estradas e os seus rumos, a vida e os seus destinos. É da tradição que nessa hora - a um só tempo de chegada e de partida - se ouça a palavra do paraninfo. Sei bem o que isso significa: antes de ser marinheiro também já fui viajante, e, passados vinte e três anos, ainda sinto aqui a presença do Professor Pereira Leite, paraninfo de minha Turma, a quem presto 